\title{
3. SEISMIC ACQUISITION SYSTEM GROUNDING AND NOISE ${ }^{1}$
}

\author{
Hartley Hoskins ${ }^{2}$ and Warren Wood ${ }^{3}$
}

\section{INTRODUCTION}

In making shipboard geophysical observations, it is important to know the acoustic and electrical background noises of the ship. Sometimes it is difficult to distinguish between them. These notes were compiled both as an aid to investigators making observations aboard the JOIDES Resolution and to identify possible noisereduction measures.

This review came out of the analysis of vertical seismic profiling (VSP) data during Leg 164. To monitor the air gun and water gun seismic sources used, we suspended a single-element hydrophone to a depth of $165 \mathrm{~m}$ from crane \#3 (frame 73, port side) and examined the spectra (Fig. 1) of the background noise in the band-pass 0-180 Hz. Schlumberger Technology Corp. (1988) was used for reference.

\section{UNDERWATER ACOUSTIC NOISE SOURCES}

\section{Engines}

The speed of seven General Motors/Electromotive Division (GM/ EMD) diesel engines is $900-910 \mathrm{rpm}(15 \mathrm{~Hz})$. The engines directly drive synchronous three-phase generators (no gearing). There are three engines running when the ship is in dynamic positioning mode. Four engines generally run when the ship is under way. This probably is the source of the $15-\mathrm{Hz}$ peaks and multiples thereof.

The engines are two-cycle V-16s, so the cylinder firing rate at 900 rpm is $240 \mathrm{~Hz}$. Two cylinders fire sequentially on alternate sides of the block, giving rise to $120 \mathrm{~Hz}$.

\section{Propellers}

The two 13-ft-diameter propellers typically run at $40-60 \mathrm{rpm}$ in the dynamic positioning mode. They have four blades. The propeller blade beats are $4-5 \mathrm{~Hz}$. There are six 750-hp Smit Slikkenveer directcurrent (DC) motors driving each propeller through a ring gear. The Philadelphia gear box ratio is $6.76: 1$. The DC motors may be the source of the 9- and $18-\mathrm{Hz}$ peaks.

\section{Thrusters}

The 12 thwartship DC-motor thrusters run at varying speeds but generally do not reverse direction for a given heading. The 6-ft, 3-indiameter propellers have four blades. The two skeg thrusters are $\sim 4$ $\mathrm{ft}$ shallower than the 10 extensible thrusters. These probably do not produce any harmonic "spikes."

\section{Pumps}

Most pumps run at $1750 \mathrm{rpm}(29 \mathrm{~Hz})$. There are three 100-hp air compressors port side aft.

'Paull, C.K., Matsumoto, R., Wallace, P.J., et al., 1996. Proc. ODP, Init. Repts., 164: College Station, TX (Ocean Drilling Program).

${ }^{2}$ Woods Hole Oceanographic Institution, Woods Hole, MA 02543, U.S.A hhoskins@whoi.edu

${ }^{3}$ Naval Research Laboratory, Code 7432, Stennis Space Center, MS 39529, U.S.A.

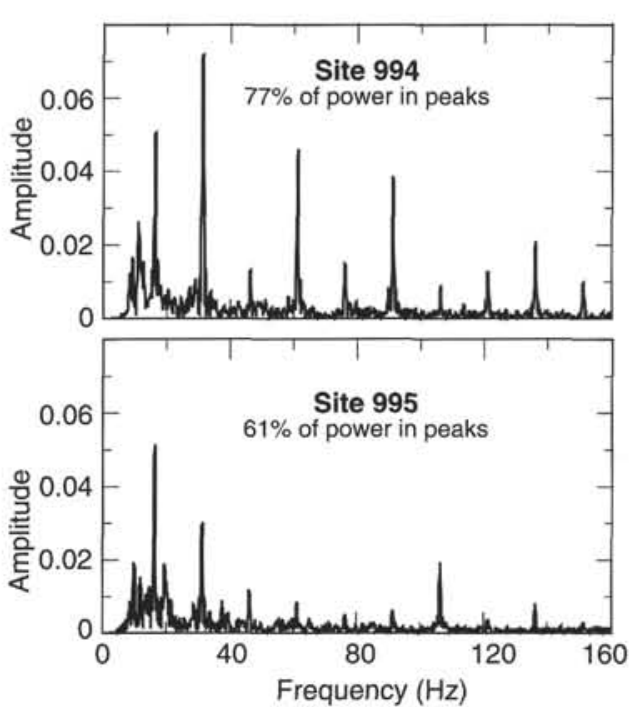

Figure 1. Amplitude spectra from VSP experiments at Sites 994 and 995 plotted at the same scale. The spectra were computed for the portion of the hydrophone data corresponding to the water column on a 750-fold stacked trace (see Fig. 2). Note the reduced level of noise at most frequencies at Site 995. These observations were taken on a calmer day during which fewer higher harmonics were excited.

\section{Wetted Area}

The draft of the ship typically decreases from 23 to $20 \mathrm{ft}$ in the course of a leg. The wetted hull area radiating sound into the water does not change appreciably $(5 \%)$.

\section{Ship's Sound Level}

The ship's root-mean-square (rms) radiated sound level reduced to 1 -m range is $\sim 207 \mathrm{~dB}$ re $1 \mathrm{~Pa}$, using a spreading loss of $44 \mathrm{~dB}$. The sensitivity of the AQ-1 hydrophone is $-202 \mathrm{~dB}$ re $1 \mathrm{~V} / \mu \mathrm{Pa}$. Given that the measurements were made only $165 \mathrm{~m}$ away from a ship $144 \mathrm{~m}$ long, the spreading loss correction is only approximate. Because most of the noise is generated in the aft engine spaces, spherical spreading is a reasonable approximation.

\section{ELECTRICAL NOISE SOURCES}

\section{Ground Datum}

The electrical ground datum on a steel-hull ship in the ocean typically varies spatially and temporally. This is because of current flows induced by movement of electrical power and a plurality of paths giving rise to ground loops. Unless minimized in a seismic recording system, these broadband variations in ground appear as noise in the signal band-pass. Measuring them is complicated.

\section{Ship's Electrical Power}

The ship has a $4160-\mathrm{V}$, three-phase bus fed by five GM/EMD diesel-driven, 2.1-MW alternating-current (AC) generators. Two other 
GM/EMD diesel-driven, 1.5-MW AC generators drive a $480-\mathrm{V}$, three-phase bus that is transformer-linked to the 4160 -V bus. The total generator capacity of the ship is $13.5 \mathrm{MW}$. At full-ahead (14 kt), the propulsion system draws $\sim 6.7 \mathrm{MW}$. Keeping station, including drilling and hotel loads, typically draws $2-4 \mathrm{MW}$.

Power for each ship activity is drawn from the two-part common bus. Eight silicon controlled rectifier ("Thyrig") banks provide DC for the two screws, 12 thrusters, and drawworks; transformers provide $480 / 240 / 120 \mathrm{~V}$ unregulated power. A synchronous motorgenerator set and two uninterruptable power supplies provide regulated bridge, dynamic positioning, and laboratory power. The 1600 hp DC motor on the drawworks can draw up to $2500 \mathrm{~A}$. One can readily hear the main engines loading when the drawworks is raising a long pipe string. The top drive DC motor is $800 \mathrm{hp}$. The cyclage of the ship's power varies $\pm 5 \%$ with load (typically higher). Equipment chassis are generally grounded to the hull, where the function is located, but return lines are not.

The power feed into the two Schlumberger logging vans is off the ship's unregulated $480-\mathrm{V}$, three-phase bus.

The silicon controlled rectifier banks probably give rise to $360-\mathrm{Hz}$ switching transients, but this is above the band-pass examined.

\section{Regulated Power}

Regulated power for all science spaces is provided from two sources:

1. A Computer Power Products brushless, synchronous revolving-field generator located port side in the after-engine room. It outputs three-phase "Y" $277 / 480 \mathrm{~V}$ with $107-\mathrm{A}$ capacity. Current draw is typically $34 \mathrm{~A}$.

2. A Cyberex uninterruptable power supply consisting of a rectifier, battery stack, and inverter located in the Koomey Room on the starboard upper tween deck of the lab stack. The output of these is three-phase "Y" $208 / 120 \mathrm{~V}, 60 \mathrm{~Hz}$. Current draw is $\sim 80 \mathrm{~A}$.

For the seismic recording equipment, this power is fed through a panel (RP-60) near the entry to the Underway Geophysics Lab. The three phases are distributed around this lab on 14 circuits. Interphase noise can be reduced by keeping all the recording equipment on one of the three phases.

The bridge and its navigational aids, including radars, are fed from the ship's emergency bus. The bridge Global Positioning System and computers are fed from the lab stack regulated power.

The ship's regulated power for the dynamic positioning system, along with the emergency generator, is located on the main deck starboard side (passageway from the lab stack to the quarters). It consists of two Westinghouse uninterruptable power supplies with singlephase $120-\mathrm{V}$ output.

\section{Ship's Active Cathodic Protection System}

The ship has an active hull corrosion control system. It consists of four 4 -in-wide, 10 - $\mathrm{ft}$-long plates. They run along each side of the ship near the stern and midship. The current flow is continuous, up to 50 A, with a supply voltage of $26 \mathrm{~V}$-about $1300 \mathrm{~W}$.

\section{Logging Cable Capacitance and Fairlead}

The seven-conductor, double-armored, 0.47-in-diameter Vector logging cable (type 7-46P) has a capacitance of $0.04 \mathrm{pF} / \mathrm{ft}$, or $\sim 1.2 \mu \mathrm{F}$, for the $10,000 \mathrm{~m}$ on the logging winch. The resistance of the cable is $10 \Omega / 1000 \mathrm{ft}$, or a total of $330 \Omega$. The armor coverage is $\sim 97 \%$.

The fairlead of the logging cable touches six points of the ship separated by $30-40 \mathrm{~m}$ : winch, sheave on the drill floor, logging heave compensator, another sheave on the drill floor, sheave at the top of tower, and the drill string. In doing so, it forms ground loops.

\section{Sonde Pre-Amplifier and Bias}

The three-channel pre-amplifier in the seismic sonde used is powered with a PML, Inc., 42- to 55-V supply which with the logging cable line drop of $15 \mathrm{~V}$ provides $36 \mathrm{~V}$ to the pre-amp. The supply ripple is less than $1 \mathrm{mV}$ rms. The current draw of the pre-amp is $\sim 24 \mathrm{~mA}$. We have two variable-gain (0-72 $\mathrm{dB}$ in five steps) pre-amplifiers built by Woods Hole Oceanographic Institution (WHOI; Hess) and two 48-dB fixed-gain pre-amps built by CSM Associates. The input and outputs are biased to $+18 \mathrm{~V}$. This bias is removed with a blocking capacitor in the three-channel attenuator box where the signal first enters the Underway Geophysics Lab. The maximum dynamic range of the pre-amplifiers is $\sim 30 \mathrm{vpp}$. Maximizing the signal gain in the sonde pre-amplifier, although running the risk of overdriving the preamp, achieves a better signal-to-noise ratio at the laboratory end. The pre-amps are electrically isolated from the tool chassis and cable armor; this is the common practice.

Because of the $300-\Omega$ line resistance, the electrical return datum of the electronics in the tool is above chassis ground, in our case by $\sim 8 \mathrm{~V}$. Any coupling-induced fluctuations in supply current are indistinguishable from signal.

\section{Grounding and Dynamic Range of Digital Acquisition System}

The RefTek digital acquisition system (DAS) model 72A-08 has an input dynamic range of $20 \mathrm{vpp}$ differential on the 24-bit channels and a 7.5-vpp differential on the 16-bit channels. The input impedance of each channel is $\sim 2 \mathrm{M} \Omega$, and six input channels have separate grounds. Because of its polyvinyl chloride case, there is no external RefTek chassis ground. The outputs of the regulated 13.8-V MG battery chargers supplying power to the RefTek's are floating. Ripple is less than one $\mathrm{mV}$ rms.

\section{Grounding Scheme}

The logging cable capacitance appears to be the dominant effective ground coupling. Given that our entire recording system in the Underway Geophysics Lab is floating, we grounded it to the logging cable armor in the winch hut by tying our pre-amplifier return (pin 5) to the armor (pins 9 and 10) in the 10-pin Cannon collector connector in the Schlumberger winch van. This is consistent with the Schlumberger logging tool procedure. The grounding consists of tying together the eight RefTek inputs and the PML pre-amp power supply.

\section{DISCUSSION}

\section{Coherent Regulated Power Noise}

Coherent noise contamination of seismic data was significant. In particular, the single-element hydrophone suspended at $165 \mathrm{~m}$ was susceptible to coherent ship noise as shown in Figure 2. At this depth, the water column contains a ship-generated signal that is typically twice the amplitude of the seafloor reflection at $3.62 \mathrm{~s}$, and certainly higher than much of the signal below the seafloor. These traces are stacks of 750 traces acquired while shooting the zero-offset VSPs at Site 994 and 995 , so the coherent components are retained while truly random noise would be attenuated by $33 \mathrm{~dB}$. Because of the coherence in the regulated power, the gain in stacking is only $\sim 16 \mathrm{~dB}$ at Site 994.

The gun repetition rate control in the trigger box is driven by its own crystal oscillator. The gun control box also has a separate oscillator with varying delays for coherently triggering several guns. Nei- 


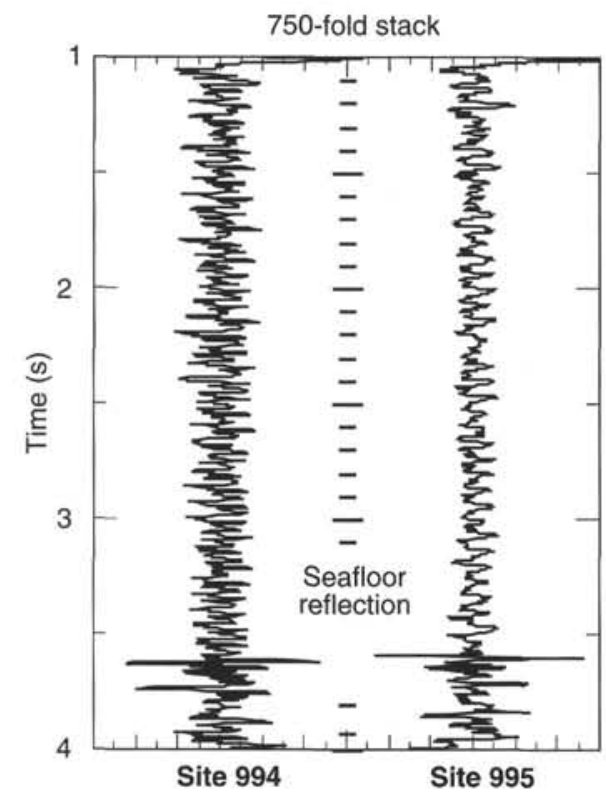

Figure 2. The stacked hydrophone traces using the 300 -in ${ }^{3}$ Bolt PAR 1500 air gun show considerable coherent noise throughout the water column, which would be expected to be quieter. Random noise, which is comparable to the seafloor reflection on the individual traces, is largely eliminated by stacking.

ther box's output has any connection to the line frequency. One would not, therefore, expect long-term coherence between the regulated power and the shot repetition rate. The observed coherence is apparently a fortuitous coincidence of the shot box and the regulated power over the several hours of the observations (taken at 10-s intervals). A shot instant randomizer was used ineffectually at Site 994 because the shifts were in increments of $100 \mathrm{~ms}$, which is an even six cycles. At Site 995, the randomizer shifts were in 10-ms increments, and the regulated power coherence noise was reduced $14 \mathrm{~dB}$; compare Site 994 and 995 in Figures 1 and 2.

\section{Spectra}

A total of 750 traces taken at Sites 994 and 995 were summed, and the amplitude spectrum is shown in Figure 1 for the traveltime interval between 1 and $3.5 \mathrm{~s}$ (just before the seafloor reflection). The spectral resolution is $1 \mathrm{~Hz}$. The energy calculation consisted of squaring the amplitude spectrum and subtracting the square of the background after notch filtering at $15-\mathrm{Hz}$ intervals.

Between $61 \%$ and $77 \%$ of the spectral energy is in a dozen relatively narrow peaks. These range across the frequency range examined, $0-160 \mathrm{~Hz}$.

Table 1 tabulates these peaks and suggests their sources. Both acoustic and electrical sources are present. Based on the identifications made in Table $1,73 \%$ of the energy in the peaks appears to be related to the engines; $8 \%$, from other acoustic sources; and $19 \%$, from electrical sources. Given that the hydrophone is nearly directly under the engines, the preponderance of engine noise is not unexpected. It is curious why the higher harmonics of the engine speed are so prevalent. There may be some subharmonics of the $240-\mathrm{Hz}$ cylinder firing frequency.

An acoustic noise/vibration analysis of the ship in the same bandpass using accelerometers and microphones in five deck and interior spaces performed by Nessler and Simpson (1984) of SDRC (Structural Dynamics Research Corporation) of Milford, Ohio, shows remarkable similarities to Figure 1. We conclude that the sources are the same, but in our case the sound is transmitted into the water through the hull. The limited shielding on our hydrophone cable also makes our measurements more prone to electrical noise.

\section{CONCLUSIONS}

Having now identified several of the components of the noise spectra as being from the ship's mechanical and electrical systems, what are the options for mitigating them?

1. The spectrum changes significantly, depending on ship's activities and weather, as can be seen by comparing the two data sets. A record needs to be kept of ship activities during the observing period to identify the noise sources. It is difficult to differentiate between acoustic and electrical noise in the pass-band of interest. They are physically intertwined.

2. Much of the noise spectrum is in narrow spikes that can be notch filtered. Notch filtering, however, can introduce phase distortions in other parts of the spectrum. Where these spikes occur in the spectrum needs to be monitored at the time of each experiment because the power and speeds of mechanical equipment will vary depending on weather, sea, and drilling conditions.

3. Because of considerable coherence in the observed ship noise over the interval between successive shots, randomization of the seismic shot instants is clearly a useful means to reduce the shipgenerated noise.

4. After applying notch filtering and shot instant randomization, stacking of repeated shots should produce a square root of $n$ signal gain.

5. Structurally, the ship is inherently noisy as minimizing acoustic radiation into the water was not an objective in its design. Significant decoupling of the noise-producing elements from the hull involves special foundation mounts and would be an enormous undertaking and not a priority in the ship's mission.

6 . The ship has ample generator capacity so that overall load fluctuations are not a limitation; rather, it is the signal line pickup, power supply ripple, and load and switching transients that give rise to electrical noise in the signal band-pass.

7. Synchronous motor-generator sets or rectifier/battery/inverter units are needed for recording instrumentation. The power requirements of newer instrumentation are generally decreasing, and their power supplies are somewhat more tolerant of line fluctuations. Several local lab or bench units, rather than one large one, may be better because this reduces noise in a longer distribution system and noise from other activities on the regulated circuits. There is more pickup from the regulated $60 \mathrm{~Hz}$ than from the unregulated power, whose frequency tended to run a little higher. In "Y" outputs, the common should be kept isolated from any chassis. Attention has to be given to balancing three-phase supplies and checking that transients and reactive loads on the other phases are not affecting the phase powering the sonde.

8. The capacitance of the logging cable is apparently the dominant ground plane coupling for sondes. Differential sonde outputs mitigate some of the ground loop noise.

9. Moving the digitization from the lab into the sonde would help reduce electrical noise, but may not be feasible depending on sonde space and the ambient temperature in the hole. Current temperature limitations are typically $70^{\circ}-85^{\circ} \mathrm{C}$ for analog-to-digital converters.

10. Where feasible, battery-powered sondes (such as the hydrophone in this experiment) obviate some noise problems deriving from power supplies feeding sondes through the logging cable.

11. Using acoustic and electrical sensors, might it be feasible to dynamically construct inverse loads or sources to counteract the certain noise sources? Active noise-canceling headsets are an example of this technology. How to do this for the main engines, which are the biggest noise source, is not evident. 
Table 1. Noise peaks and probable sources.

\begin{tabular}{cll}
$\begin{array}{c}\text { Frequency } \\
\text { (Hz) }\end{array}$ & \multicolumn{1}{c}{ Acoustic source } & Electrical source \\
\hline 9 & DC motors driving propeller shafts (bull gear ratio 6.76:1) & \\
15 & Main engines (900 rpm) & \\
18 & DC motors driving propeller shaft (first harmonic) & \\
29 & Pumps and compressors (1750 rpm) & Regulated ship's power \\
30 & Main engines (first harmonic) & \\
45 & Main engines (second harmonic) & Unregulated ship's power \\
60 & & \\
60 & Main engines (third harmonic) & \\
61 & & Regulated ship's power (first harmonic) \\
75 & Main engines (fourth harmonic) & Unregulated ship's power (first harmonic) \\
90 & Main engines (fifth harmonic) & \\
105 & Main engines (sixth harmonic) & \\
120 & Main engines (seventh harmonic) & \\
120 & & Regulated ship's power (second harmonic) \\
122 & & Unregulated ship's power (second harmonic) \\
135 & Main engines (eighth harmonic) & \\
150 & Main engines (ninth harmonic) & \\
185 & Main engines (10th harmonic) & \\
183 & &
\end{tabular}

12. Some procedure to determine background for each seismic experiment would be helpful to investigators. Although developing a consensus among disparate applications is difficult, we all lose for the lack of this information. The two figures in this report are examples of simple noise measures and are not difficult to prepare.

\section{ACKNOWLEDGMENTS}

Thanks are due to Chief Engineer Arno Jacobsen, Electrical Supervisor Phillip Gardner, and Schlumberger Engineer Steve Kittredge in gathering this information.

\section{REFERENCES}

Nessler, G.L., and Simpson, M.A., 1984. Sedco/BP-471 Noise/Vibration Investigation: Milford, OH (Structural Dynamics Research Corp.), project number 12077 .

Schlumberger Technology Corp., 1988. Sedco/BP 471, Mobile Offshore Drilling Unit-Dynamically Stationed Drillship, Construction Portfolio: Dallas, TX (Schlumberger Tech. Corp., Dallas Engineering). 